\title{
THE DIAGNOSIS OF PERTUSSIS WITH SUPRALARYNGEAL AND MODIFIED PERNASAL SWABS
}

\author{
BY \\ ANDREW BOGDAN \\ From the Department of Paediatrics and Child Health, University of Leeds
}

(RECEIVED FOR PUBLICATION MAY 6, 1957)

This paper analyses the results of diagnostic swabs taken from children seen at a pertussis contact clinic between December, 1950, and April, 1952.

Two new diagnostic techniques entailing contaminating swabs by cough, which were developed during this period, yielded a high percentage of positive cultures. A preliminary communication on one of these new techniques was published when the initial results of supralaryngeal swabs suggested their value (Bogdan, 1951c). The other technique, that of a modified pernasal swab used concurrently with a supralaryngeal swab, was developed in the course of this study and is described for the first time in this paper.

\section{Method of Inquiry}

Swabs were taken from the children, whose ages varied between 4 months and 9 years, whenever they attended the clinic, which was held three times a week. Much care was taken to ascertain the diagnosis, infectivity and stage of illness when swabs were taken.

Swabs were sent within three to five hours to the Department of Bacteriology of the Westminster Medical School where diamidine-penicillin-fluoride culture medium (Lacey, 1954) was routinely used. Negative cultures of swabs were reported to the clinic after 96 hours' incubation; positive cultures were not infrequently reported after 48 or 72 hours' incubation.

\section{Method of Ascertaining Infectivity}

Some children were free of symptoms and, though contacts, had actually escaped infection. Their swab cultures were negative and no carriers were detected. Some children already had a paroxysmal cough or were whooping. These continued to attend until they were symptom free. Some children were contacts with a brief but definite history of catarrhal symptoms and a mild persistent cough, which later became paroxysmal. They continued to attend the clinic until they lost all their symptoms. This prolonged observation enabled the observer to become certain on clinical grounds which children had pertussis and so acquire a reasonably reliable series of 'known' cases which are referred to below.

Some of the children were given suppressive treatment, as described previously, with chloramphenicol (Bogdan, 1951a and b) or with terramycin (Bogdan, 1952) after diagnostic swabs had been taken. Later swabs taken from these children are excluded from this survey. In view of waning infectivity, no swabs from untreated children taken later than the tenth day of the paroxysmal stage are considered for this survey.

In the circumstances every swab from each known case was considered capable of yielding a positive culture of Haemophilus pertussis, thus enabling the accuracy of each swab technique or combination of swab techniques to be assessed.

\section{Method of Ascertaining Stage of Illness}

Considerable care was taken in each case to ascertain how long each child had had symptoms such as nasal catarrh or a mild simple cough which, though persistent, only occurred occasionally, as if the throat were being cleared. This was taken as evidence of the pre-paroxysmal stage of the illness.

The onset of the paroxysmal stage was indicated when eventually the cough had changed in character and became paroxysmal and spasmodic, frequently terminating in a whoop and at times associated with vomiting at the end of each spasm.

Each type of cough was demonstrated for the mother's guidance to ensure that she understood the difference between a simple and a paroxysmal cough; it was thus possible to gather from the mother at what stage of the illness swabs were taken.

\section{Preliminary Analysis: Pernasal and Postnasal Swabs}

Pernasal swabs were taken in the manner described by Bradford and Slavin (1940), while postnasal 
swabs were taken in the manner described by Cruickshank (1944).

The diagnostic accuracy obtained when pernasal and postnasal swabs were routinely used is seen from the swab culture results of 110 pairs of swabs from known cases of pertussis (Table 1).

TABLE 1

RESULTS OF PERNASAL AND POSTNASAL SWABS FROM KNOWN CASES OF PERTUSSIS

\begin{tabular}{|c|c|c|c|c|}
\hline Technique & $\begin{array}{c}\text { Incubation } \\
\text { Period }\end{array}$ & $\begin{array}{c}\text { Preparoxysmal } \\
\text { Stage }\end{array}$ & $\begin{array}{l}\text { Paroxysmal } \\
\text { Stage } \\
(1-10)\end{array}$ & Total \\
\hline \multirow{4}{*}{$\begin{array}{l}\text { Total pairs taken } \\
\text { Per and/or post- } \\
\text { nasal positive } \\
\text { Pernasal positive } \\
\text { Postnasal posi- } \\
\text { tive .. } \\
\text { Both negative ... }\end{array}$} & 5 & 65 & 40 & 110 \\
\hline & $\begin{array}{l}4 \\
2\end{array}$ & $\begin{array}{l}53(81 \%) \\
39(60 \%)\end{array}$ & $\begin{array}{l}28(70 \%) \\
22(55 \%)\end{array}$ & $\begin{array}{l}85(77 \%) \\
63(57 \%)\end{array}$ \\
\hline & 3 & $44(67 \%)$ & $19(57 \%)$ & $66(60 \%)$ \\
\hline & 1 & 12 & 12 & 25 \\
\hline
\end{tabular}

In $77 \%$ (or $85 / 110$ ) pairs one or both swabs were positive: $57 \%$ (or $63 / 110$ ) of the pernasal swabs were positive: $60 \%$ (or $66 / 110$ ) of the postnasal swabs were positive. In the preparoxysmal stage a higher proportion of positive cultures was obtained than after the onset of paroxysms, thus indicating the value of swab diagnosis at this important stage of the illness.

\section{Supralaryngeal Swab Technique}

The possibility of improving on these results led to the second part of this investigation and the development of the new supralaryngeal swab technique for the diagnosis of pertussis.

For supralaryngeal technique a normal straight swab is used with the mount made of either wood or wire, preferably the latter. The child is seated on the mother's knee so that it faces the doctor. The mother holds both the child's hands in one of her own and places the other firmly on its forehead, holding the child's head well back to enable the swab to be held directly above the lumen or upper end of the larynx (Fig. 1). The tongue is depressed by a broad spatula and the child is asked to cough. The direct positioning of the swab over the laryngeal outlet helps the doctor considerably in his attempt to obtain a freshly expectorated portion of mucus from the larynx. In order to obtain the mucus, correct positioning of the child and the swab is important.

If a child does not cough when asked, coughing can be provoked by touching the fauces or pharyngeal wall with the spatula, especially when the head is held well back which lessens the risk of vomiting. Towards the end of this trial, when more care was taken to ensure that a portion of mucus was adherent to each swab, results became increasingly positive.

An explanation to older children and parents that the procedure entails no more than 'coughing into a little stick' helped to inspire confidence and cooperation.

Absolute inability on the part of a child to cough, in spite of an attempt having been made with spatula and swab to provoke cough, provided reasonable evidence of insensitivity of the throat. This is most unlikely in pertussis, allowance being made for the early part of the incubation period. Thus this supralaryngeal technique may yield not only bacteriological evidence of pertussis, but provide clinical evidence against pertussis in some cases.

When an obvious portion of laryngeal mucus has been obtained on a supralaryngeal swab in catarrhal conditions other than pertussis, and symptomatic treatment with ephedrine-saline nasal drops and simple linctus had been begun, a negative culture report at 96 hours usually coincided with improvement in catarrh and cough. Quarantine of contacts in whom this was noticed was then curtailed. In no instance did subsequent events show that this course of action had been unjustified.

\section{Supralaryngeal Results}

During a period of 17 months 340 supralaryngeal swabs were taken from 174 known cases of pertussis. As with the series of pernasal and postnasal swabs described above, all these were taken before the eleventh day of the paroxysmal stage and before treatment. Of the entire series of supralaryngeal swabs, $65 \%(224 / 340)$ yielded positive cultures, 64 being positive in the first hundred, 51 in the second and 72 in the third. In the last 40 swabs only three

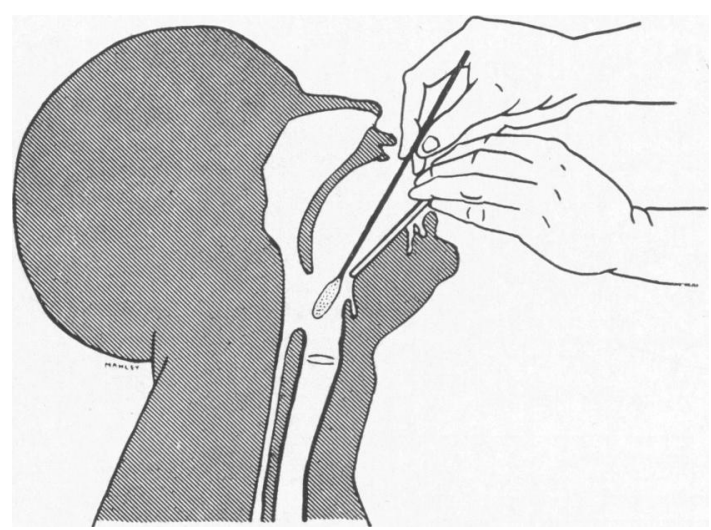

FIG. 1.-Position of head and swab when supralaryngeal swab is being contaminated by cough. 
failed to yield a positive swab culture (Table 2), achieving a diagnostic accuracy of $92.5 \%$.

TABLE 2

RESULTS OF 340 SUPRALARYNGEAL SWABS TAKEN FROM 174 CHILDREN WITH KNOWN PERTUSSIS

\begin{tabular}{c|c|c|c}
\hline \multirow{2}{*}{$\begin{array}{c}\text { Number of } \\
\text { Children }\end{array}$} & $\begin{array}{c}\text { Number of } \\
\text { Swabs }\end{array}$ & $\begin{array}{c}\text { Single Suparlaryngeal Swab } \\
\text { Cultures in Diamidine-penicillin- } \\
\text { fluoride Medium }\end{array}$ \\
\cline { 2 - 3 } & & Positive & Negative \\
\hline 54 & 100 & 64 & 36 \\
44 & 100 & 51 & 49 \\
53 & 100 & 72 & 28 \\
23 & 40 & $37(92 \cdot 5 \%)$ & 3 \\
\hline 174 & 340 & $224(65 \%)$ & 116 \\
\hline
\end{tabular}

A new technical assistant helped to take the second hundred swabs. This may account for a temporary lessening in accuracy and subsequent improvement with experience in the third hundred cases. This prolonged trial of supralaryngeal swabs suggest that they are no less accurate than pernasal or postnasal swabs using diamidine-penicillinfluoride selective medium cultures in all cases.

\section{Comparison of Swab-Technique}

To compare the results of supralaryngeal swabs with those obtained with pernasal and postnasal swabs an analysis was made of 109 known cases from whom three types of swabs were taken simultaneously.

The 'triple-swab' routine used at this stage of the investigations was as follows:

(1) A postnasal swab was taken first (from the nasopharynx behind the uvula).

(2) A short nasal swab was then passed into the nasopharynx and left there.

(3) A supralaryngeal swab was taken next, using a simple throat swab.

(4) The pernasal swab was then withdrawn.

The normal routine of taking pernasal swabs was modified to prolong the opportunity for each swab to become effectively contaminated in the nasopharynx. The likelihood of this having taken place was further increased by continued exposure of each pernasal swab to the cough provoked for the supralaryngeal swab. The actual swabs were modified in one further detail. A $4 \frac{1}{2}$ in. length of wire was used for taking pernasal swabs as this was found to be easier to introduce, less flexible and less likely to fall out.

By using this 'triple-swab' routine in taking swabs from known cases of pertussis, the diagnosis was confirmed bacteriologically in 92 ( $84 \%$ ) of 109 cases (Table 3).

The postnasal swab alone confirmed the clinical diagnosis on $43 \%(47 / 109)$ occasions, supralaryngeal swabs on $55 \%(60 / 109)$ occasions and pernasal swabs (used in this modified way) on $72 \%(79 / 109)$ occasions.

Analysis of these results showed that the supralaryngeal and modified pernasal swab between them confirmed the diagnosis in $84 \%(92 / 109)$ of the known cases. The additional use of a third swab technique, a postnasal swab, had not increased the diagnostic accuracy of swabs in this series. This is noteworthy as further positives have usually been detected by each additional method employed whenever comparison has been previously made of diagnostic techniques used in pertussis.

The combination of a pernasal swab with a supralaryngeal swab therefore provides the best routine for obtaining positive cultures, when it is not possible to obtain a reasonable portion of fresh mucus on to a supralaryngeal swab.

\section{Summary}

Supralaryngeal swabs were taken from early known cases of pertussis. Positive culture reports from these swabs indicated an overall individual swab accuracy of $65 \%(224 / 340)$, attaining an accuracy of $92.5 \%$ at the end of the series. This technique is illustrated and described in detail.

A new modified pernasal swab technique to use with supralaryngeal swabs is described.

The new combination of a modified pernasal and a supralaryngeal swab had a diagnostic accuracy of $84 \%(92 / 109)$.

TABLE 3

TRIPLE-SWAB ROUTINE IN 109 KNOWN CASES OF PERTUSSIS

\begin{tabular}{|c|c|c|c|c|c|c|c|}
\hline \multirow{2}{*}{\multicolumn{3}{|c|}{ Stage of Illness }} & \multicolumn{2}{|c|}{ Children } & \multirow{3}{*}{$\begin{array}{c}\begin{array}{c}\text { Modified Pernasal } \\
\text { Positive }\end{array} \\
27(75 \%) \\
\end{array}$} & \multirow{3}{*}{$\begin{array}{c}\begin{array}{c}\text { Postnasal } \\
\text { Positive }\end{array} \\
17(46 \%)\end{array}$} & \multirow{3}{*}{$\begin{array}{c}\begin{array}{c}\text { Supralaryngeal } \\
\text { Positive }\end{array} \\
19 \frac{(53 \%)}{(53 \%)}\end{array}$} \\
\hline & & & \multirow{2}{*}{$\begin{array}{c}\text { Total } \\
36\end{array}$} & \multirow{2}{*}{$\begin{array}{c}\text { Positive } \\
30\end{array}$} & & & \\
\hline Preparoxysmal .. & $\cdots$ & $\cdots$ & & & & & \\
\hline Paroxysmal (1-10) & $\cdots$ & $\cdots$ & 73 & 62 & $52(71 \%)$ & $30(41 \%)$ & $41(56 \%)$ \\
\hline Totals & $\ldots$ & $\cdots$ & 109 & $92(84 \%)$ & $79(72 \%)$ & $47(43 \%)$ & $60(55 \%)$ \\
\hline
\end{tabular}


Both new techniques depend on better contamination by cough of the swab. The importance of some laryngeal mucus adhering to supralaryngeal swabs is stressed.

All swabs were cultured on diamidine-penicillinfluoride selective medium.

I am indebted to Dr. B. W. Lacey for the culture reports, to Dr. N. O. Richards under whose supervision the clinical work was done, to Dr. Charles F. Harris and Professor W. S. M. Craig for advice and encouragement, to Miss Anne Wigley and Miss Pamela Bennett of the British Red Cross Society for much skilled help assisted by Mrs. Hill; also to Miss Wendy Major for secretarial assistance and Miss Manley for the illustration.

The clinical part of this study was carried out with the aid of the Mary Scharlieb Research Studentship of the University of London at the Westminster Children's Hospital: the analysis of results in the Department of Paediatrics and Child Health, University of Leeds.

\section{REFERENCES}

Bogdan, A. (1951a). Proc. roy. Soc. Med., 44, 1065. (1951b). Lancet, 1, 764.

(1951c). Ibid., 2, 1204.

- (1952). Brit. med. J., 2, 1186.

Bradford, W. L. and Slavin, B. (1940). Proc. Soc. exp. Biol. (N.Y.), 43, 590.

Cruickshank, R. (1944), Lancet, 1, 176.

Kristensen, B. (1933). J. Amer. Med. Ass., 101, 204.

Lacey, B. W. (1954). J. Hyg. (Lond.), 52, 273. 